\title{
EL TURISTA Y SUS GARANTÍAS JURÍDICAS EN EL ORDENAMIENTO PRIVADO ESPAÑOL
}

\author{
Eduardo Sánchez Álvarez ${ }^{1}$ \\ Profesor Asociado de Derecho Civil \\ Universidad de Oviedo \\ sanchezaeduardo@uniovi.es
}

(Fecha envío: 28/10/16 - Fecha aceptación: 16/05/17)

\section{Resumen}

Partiendo de la relevancia objetiva que la normativa jurídica que rige el fenómeno turístico ostenta, en particular desde la óptica del Derecho Privado, y considerando qué garantías el Ordenamiento jurídico español brinda al turista, el presente trabajo busca cubrir dos aspectos fundamentales. Por una parte, recorrer descriptivamente cuáles son esas garantías jurídicas genéricas, las cuales habrán de ser proyectadas concretamente sobre la figura del turista para observar su encaje con él. Por otra, tras ese análisis y a la vista de su resultado, proponer ineludibles mejoras que nos permitan proclamar verazmente que el turista cuenta con un respaldo jurídico a las vicisitudes que a raíz de tal condición jurídica pueda experimentar o, tantas veces, sufrir.

\section{Palabras clave}

turista, conciliación, mediación, arbitraje, jurisdicción

\section{Abstract}

In view of the importance of the laws and regulations governing tourism, especially in the area of Private Law, and considering what guarantees are offered to tourists by the legal system, this paper aims to cover two key aspects. On the one hand, it gives a comprehensive description of these generic legal guarantees, with a particular focus on their impact on tourists as legal objects. On the other hand, in light of the results of this analysis, it proposes imperative improvements that, once in place, would offer true, effective legal recourse to any difficulties arising from their legal condition as tourists.

\section{Key words}

tourist, conciliation, mediation, arbitration, jurisdiction

\section{PLANTEAMIENTO}

Constatar la relevancia que para España tiene el turismo es una auténtica obviedad. Los atractivos que atesora nuestro país son innegables: historia, cultura, arte, gastronomía, naturaleza, benignidad climática, variedad y riqueza paisajística... La industria turística española es poderosa, puesta al servicio de un aprovechamiento y explotación sostenible de todos esos activos. Y su labor es fundamental para la propia supervivencia económica nacional, al erigir una de las primordiales fuentes de ingresos con las que podemos contar. Sin el turismo serían notoriamente peores nuestro desarrollo y progreso social, el nivel de empleo...

Por lo tanto, es absolutamente perentorio que España cuide su industria turística y que ésta, a su vez, se esfuerce con máxima prestancia y dedicación para la conformación de un sistema capaz de dejar satisfecho al turista que interactúe con él, haciendo que su experiencia sea positiva.

De esa idea introductoria ya se deduce que la calidad del sistema turístico, siendo un concepto poliédrico y poco tangible por aglomerar en sí bajo criterios plurales factores muy dispares a testar ${ }^{2}$, es sin embargo un objetivo

\footnotetext{
${ }^{1}$ Doctor en Derecho por la Facultad de Derecho de la UNED (Madrid), premio extraordinario de doctorado. Profesor Asociado de Derecho Civil

2 "Sobre el turismo convergen diferentes disciplinas fruto de las distintas relaciones (...) que se proyectan sobre esta materia", en un tangible "contexto de multidimensionalidad del fenómeno turístico" (BAUZÁ MARTORELL, 2014: "Hacia una legislación básica en materia de turismo. A propósito de las centrales electrónicas de reservas turísticas", Diario La Ley, no 8319 , de 27 de mayo). "El turismo se ha venido configurando, tradicionalmente, como un fenómeno de carácter multidisciplinar y transversal. El turismo, en cuanto fenómeno con una importante incidencia en la vida socio-cultural, económica y política de un país y por su heterogeneidad, puede ser objeto de estudio y análisis desde diferentes campos del saber: la Economía, la Geografía, la Sociología y, por supuesto, el Derecho" (PÉREZ FERNÁNDEZ, 2004: 21, "Derecho Público del Turismo", Thomson-Aranzadi, Pamplona).
} 
que ha de inspirar la solvencia e importancia que esta actividad porta consigo. $Y$ uno de esos elementos que ha de coadyuvar a su consecución es el que aporta el Derecho, la vertiente jurídica que se aneja al fenómeno turístico.

En este trabajo se busca reflexionar con ánimo expositivo y crítico respecto a un aspecto concreto que se integra en ese ámbito jurídico anexo al turismo: las garantías que el Ordenamiento jurídico privado interno español arbitra e implementa para hacer valer derechos y obligaciones que en su seno se hallen. La suficiencia de estos instrumentos ha de estar fuera de toda duda, pues en caso contrario la quiebra de la ladera jurídica del Sistema turístico es factible aunque inaceptable.

Para ubicar adecuadamente el objeto de estudio propuesto, se hará brevemente una mención al Derecho del Turismo, cuál puede ser su concepto y contenido, las dificultades que conlleva su hibridez o dualidad académica y sus consecuencias. Acto seguido, se tratará de esquematizar cuáles son esos posibles cauces aseguratorios y reparadores a seguir. Posteriormente, se propondrá propulsarlos críticamente sobre el fenómeno turístico para comprobar si se ajustan a sus peculiaridades y, por fin, se valorará su adecuada efectividad para proteger los intereses del turista en cuanto cualificado y específico consumidor que, a la postre, apontoquen la certera solidez de una de las vigas maestras de la Economía nacional.

\section{SUCINTA REFERENCIA AL DERECHO DEL TURISMO Y SUS PRINCIPALES NOTAS CARACTERÍSTICAS}

Ante todo, hay que observar sucintamente qué entender por Derecho del Turismo y repasar algunas de las dificultades, incluso ontológicas, que le circundan.

\subsection{Hibridez académica}

Cabe definir el Derecho del Turismo como "el conjunto de normas que son de aplicación para la regulación de las actividades y los servicios turísticos y los sujetos que intervienen en la misma"3. Estamos enfrentando una pluralidad de normas jurídicas que, a mayor complejidad, difícilmente pueden gozar de una autonomía científica plena, habida cuenta que en este sector conviven normas de filiación dispar: Derecho Público (su ordenación administrativa, la acción gubernativa de su fomento, ámbito disciplinario y sancionador, etc.) y Derecho Privado (básicamente, las diferentes modalidades de figuras contractuales turísticas) ${ }^{4}$. Con todo, un considerable número de autores defiende esa autonomía con fundamento en "las peculiaridades de los negocios jurídicos propios del sector, así como en las exigencias específicas del establecimiento de vínculos jurídicos por medio de contratos tipo", pues la presencia de "normas que regulan la actividad turística, protegiendo como tal a las personas que con motivo de sus desplazamientos o estancias temporales a un determinado lugar fuera de su entorno habitual y que realizan actividades de ocio sin obtener remuneración alguna, justifican su existencia"6. Visualizamos la primera dificultad relevante de esta realidad jurídica: su dualidad o hibridez. Para su integral comprensión hay que acudir a distintas ramas del Derecho que convergen en este multidisciplinar fenómeno?.

\subsection{Erogación competencial y sus consecuencias}

En el diseño constitucional español, no se reserva al Estado como competencia absolutamente propia la materia del turismo. El art. 148.1.18으 de la Constitución (CE) dispone que sea competencia autonómica la promoción y ordenación del turismo en su ámbito territorial ${ }^{8}$. Nos hemos encontrado así con una contrariedad en quien habita una indudable inseguridad jurídica: una disformidad legislativa de normas estatales y autonómicas de distinto rango coexistiendo en previsible inarmonía, a las que habría que añadir incluso normativa comunitaria europea ${ }^{9}$.

\footnotetext{
${ }^{3}$ RAMALLO MIÑÁN, 2013: 18, “Manual básico del Derecho Turístico”, Tecnos, Madrid.

${ }^{4}$ Minuciosamente, BLANQUER CRIADO, 1999: “Derecho del Turismo”, Tirant lo Blanch, Valencia; CORCHERO PÉREZ, 2008: "Derecho del Turismo. Conceptos fundamentales", lustel, Madrid.

${ }^{5}$ PÉREZ FERNÁNDEZ, 2004: 35, “Derecho Público...”, cit.

${ }^{6}$ CARRIZO AGUADO, 2016: 2. "Aspectos jurídicos del contrato de aprovechamiento por turno de bienes de uso turístico ante su comercialización en la esfera internacional”, Internacional Journal of World of Tourism”, nº 5, vol, 3.

${ }^{7}$ En profundidad, FERNÁNDEZ PÉREZ, 2015: 19-37. “El turismo como fenómeno objeto de regulación”, en FRANCH FLUXÁ (dir.) "Manual de Contratación Turística", Atelier, Barcelona.

8 Vid. RODRIGUEZ-ARANA MUÑOZ, 2001: "La distribución de competencias en materia de turismo", Revista de Documentación Administrativa, no 259-260.

${ }^{9}$ V. gr. Directiva (UE) 2015/2302 del Parlamento y del Consejo, de 25 de noviembre, relativa a los viajes combinados y a los servicios de viaje vinculados.
} 
Tampoco parece que el legislador estatal pueda acogerse en su normación a la cláusula de reserva residual que prevé el art. $149.3 \mathrm{CE}^{10}$.

Que una de las primordiales industrias del país se encuentre tan endeble y dispersamente regulada no es un factor positivo ${ }^{11}$. Y parece sensato replantearse una normación mucho más armonizada ${ }^{12}$-infra-.

\subsection{Su perspectiva desde el Derecho Privado}

Integran el Derecho del Turismo normas de Derecho Civil y Mercantil ${ }^{13}$. En ellas se insertan previsiones relativas a sujetos privados ligados a la actividad turística y algunas figuras contractuales que tienen este ámbito por su objeto de desenvolvimiento.

\section{a) Prisma subjetivo}

Cabe destacar ante todo al turista. Se trataría de una personificación ratione materiae del consumidor, en tanto persona (natural o jurídica) que solicita, contrata y/o disfruta, en condición de destinatario final, de servicios de índole turística. No relatamos un consumidor sin más, sino un consumidor cualificado con un estatuto jurídico léase, un conjunto de derechos y obligaciones- asimismo singularizado ( $v$. gr. recibir prestaciones congruas con el establecimiento turístico con quien haya contratado alojamiento y servicios, aseguramiento de sus derechos personales mientras se halle en el mismo, información precontractual acorde al tipo de relación jurídica que se traba...). Su salvaguarda viene ya exigida por el art. $51 \mathrm{CE}$, al prever el principio general de protección de

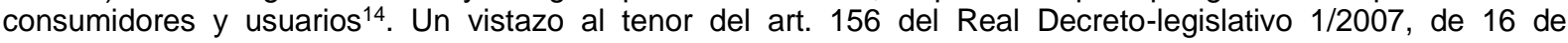
noviembre, por el que se aprueba el Texto refundido de la Ley general para la defensa de los consumidores y usuarios y otras leyes complementarias (DCU), al introducir "información adicional sobre el viaje contratado" que deberá perentoriamente facilitarse al turista/consumidor que esté en trance de contratar un viaje combinado, es argumento suficiente para comprobar la certeza de este extremo. Además, ha de realzarse un aspecto medular en la condición del turista: su remarcada fragilidad apegada a la condición esencial de tratarse de una persona que se halla "desplazada de su entorno y que presenta dificultades y problemas que denotan su vulnerabilidad y sensibilidad, derivándose por tal necesidad de un sistema específico de protección"15.

Igualmente, ha de referirse la figura del empresario turístico, en cuanto aquél que, realizando esa actividad de comercio, la enfoca hacia este sector con asunción del correlativo estatuto a él apegado. Mutatis mutandis, análogamente al turista, esa actividad configurará y particularizará su posición jurídica bajo igual criterio material u objetivo.

\section{b) Prisma contractual}

A nuestra disciplina le interesa también acotar las modalidades contractuales que acoge en sí, partiendo de la teoría general del contrato del Código Civil (CC) y llegando a las especificidades propias del giro turístico, previo paso por modulaciones como la que puede imprimir el fenómeno de los contratos de adhesión y las condiciones generales de la contratación que en ellos suelen anidar con frecuencia. Asimismo, los contratos a valorar podrán gozar de carácter civil (regulados en leyes civiles y suscritos entre personas, naturales o jurídicas, ubicadas fuera de la actividad empresarial) o mercantil (insertos en el tráfico empresarial y reglados por normas mercantiles 0 , supletoriamente, civiles). Por ejemplo, el DCU regula en detalle el contrato de viaje combinado en sus arts. 150 a 165, ambos inclusive.

\footnotetext{
${ }^{10} \mathrm{El}$ art. $149 \mathrm{CE}$ "no contiene ninguna reserva competencial a favor del Estado sobre el turismo (...) Siendo esto así, no tiene por qué entrar en juego la cláusula de reserva residual del art. 149.3 de la CE (...) puesto que los Estatutos de las Comunidades (...) sí que han sido cauce explícito de asunción de las competencias sobre turismo", si bien en ámbitos como el tratado se engarza "un inevitable grado de indeterminación" que hace que cuente con "dimensiones clasificables dentro de otro concepto material y encajables en otro título competencial" (STC 125/1984, de 20 de diciembre, FJ $1^{\circ}$ ).
}

11 Vid. ROCA ROCA; CEBALLOS MARTíN y PÉREZ GUERRA, 1998: "La regulación jurídica del turismo en España", Universidad de Almería.

12 Cfr. PÉREZ FERNÁNDEZ, 2012: "La armonización de la legislación turística", III Congreso Internacional de Derecho del Turismo, Palma de Mallorca.

${ }^{13}$ En detalle, BARBA DE VEGA y CALZADA CONDE, 2004: "Introducción al Derecho Privado del Turismo", Thomson-Aranzadi, Pamplona.

14 "El precepto, al imponer a los poderes públicos la obligación de garantizar la defensa de los consumidores y usuarios, protegiendo mediante procedimientos eficaces, la seguridad, la salud y los legítimos intereses económicos de los mismos (...) no (...) puede desconocer que la construcción de un sistema eficaz de resolución extrajudicial de litigios permite ampliar las posibilidades de salvaguarda de los legítimos intereses de los consumidores y usuarios a través de procedimientos eficaces" (ESPÍN ALBA, 2013: 2, "Arbitraje y mediación de consumo: a propósito de la Ley 16/2011, de 24 de junio, de contratos de crédito al consumo", Boletín del Ministerio de Justicia, $\mathrm{n}^{\circ} 2160$, Madrid).

${ }^{15}$ CARRIZO AGUADO, 2016: 2. “Aspectos jurídicos...", cit. 


\section{MECANISMOS DE PROTECCIÓN GENÉRICOS EN EL ORDENAMIENTO JURÍDICO-PRIVADO ESPAÑOL}

Procede ahora desgranar cuáles son los instrumentos implementados genéricamente en el ámbito del Derecho Privado para la veraz aseveración y ejecución de derechos y obligaciones surgidos a raíz de relaciones contractuales (de ser precisa) en caso de un incumplimiento o cumplimiento defectuoso, desembocando en una situación conflictual. Nos ceñimos solamente a los arbitrados en nuestro Ordenamiento interno, si bien hemos de dejar apuntado que no debe obviarse que en este ámbito abundará con previsible profusión la componente extranjera o transnacional, por lo que el sector turístico y su regulación jurídica a buen seguro constituirá objeto de análisis académico por parte del Derecho Internacional Privado y su normativa propia.

Han de destacarse cuatro cauces que sirven a esa finalidad, escindibles en dos grupos fundamentales tomando como criterio clasificatorio el papel más o menos intervencional que un tercero ajeno al núcleo de intereses en conflicto, pero llamado para participar en su resolución, puede desplegar. Cabe hablar de técnicas autocompositivas y heterocompositivas.

Las autocompositivas conllevan que sean las mismas partes en conflicto quienes acaben por hallarle una solución desde sus propias capacidades de negociación, acuerdo, transacción... Aunque siempre concurra una tercera persona en ellas, la decisión final para superar la controversia nacida es exclusiva de esas partes. Dentro de este grupo, destacamos dos figuras: la conciliación y la mediación. Caso de no prosperar fructíferamente estas modalidades, quedaría expedito acudir a los mecanismos heterocompositivos.

Las técnicas heterocompositivas dotan de un protagonismo neurálgico a esa tercera persona a quien se somete el supuesto litigioso en curso, que decide vinculante y finalmente la solución a darle. En ellas, se aglutinan el arbitraje y la Jurisdicción. De otro modo, ratione personae, observamos al árbitro y al Juez, respectivamente.

No haremos referencia detallada a una vía puramente administrativa, de Derecho Público, que consiste en la reclamación al órgano de la Administración correspondiente (escrito u hoja preestablecida de reclamaciones), pues entendemos que sin perjuicio de que se incoe expediente sancionador al empresario turístico presunto infractor, el turista no es parte rigurosamente en su curso.

Igualmente, pueden clasificarse esos medios en no judiciales (mecanismos ADR -Alternative Dispute Resolution-, arbitraje, conciliación y mediación) y judiciales (la Jurisdicción).

Una vez más, apreciaremos una sensible dispersión normativa, visto que su regulación se encuentra en distintas normas jurídicas.

\subsection{Mecanismos autocompositivos}

Son técnicas de resolución de conflictos donde se aplica la voluntad de las partes con intereses contrapuestos, engarzadas al espectro de la transacción de naturaleza contractual. Cuentan con estos rasgos: no adversativas, extrajudiciales, alternativas y privadas.

Debe distinguirse a la mediación de la conciliación. El principal criterio distintivo entre ambas estriba en el grado de intensidad de las facultades intervencionales del tercero ante quien se acude en pos de la superación de un conflicto gestado. Siendo en ambos casos la sola voluntad de las partes en contraposición la que mediante un acuerdo lo zanje, en la conciliación el tercero se ciñe a procurar un acercamiento de los contendientes. Mientras, en la mediación, además, ese tercero adopta una postura mucho más activa hacia las partes, proponiendo, asesorando ${ }^{16} \ldots$

\section{a) Conciliación}

MONTERO AROCA ${ }^{17}$ entiende por conciliación la comparecencia obligatoria o voluntaria de las partes ante una autoridad para, a su presencia, tratar de solucionar el conflicto que les separa, con los efectos que el Ordenamiento jurídico reconozca al acuerdo que pueda alcanzarse.

\footnotetext{
16 "Estas soluciones autocompositivas se pueden alcanzar por las propias partes o por la intervención de un tercero, pero las partes no están vinculadas por lo que pueda plantear el tercero. La intervención puede consistir en intentar aproximar las posturas de las partes en conflicto y que sean ellos los que obtengan la solución (conciliación), bien en sugerir, proponer o plantear diferentes salidas al conflicto, manejando cualquier posibilidad, con el fin de que las partes puedan acoger alguna de ellas y de este modo poner fin al litigio (mediación)" (IGLESIAS CANLE, 2011: 69. "Formas de solución de conflictos tras la Ley 13/2009, de 3 de noviembre: especial referencia a la conciliación y mediación", Dereito, vol. 20, $n^{\circ} 2$, Universidad de Santiago de Compostela).
}

${ }^{17}$ MONTERO AROCA, 2000: 346. "Derecho Jurisdiccional", Tirant lo Blanch, Valencia. 
La regulación presente de la conciliación se encuentra en la Ley 15/2015, de 2 de julio, de Jurisdicción voluntaria (LJV); concretamente en sus arts. 139 a 148, ambos inclusive ${ }^{18}$, indicando que "se podrá intentar la conciliación (...) para alcanzar un acuerdo con el fin de evitar un pleito".

Por lo que se refiere a la competencia para conocer de los actos de conciliación, le corresponde bien al Juez de Paz, bien al letrado de la Administración de Justicia del Juzgado de Primera Instancia o del Juzgado de lo Mercantil (si en este segundo supuesto se tratara de materias de su ámbito objetivo) del domicilio del requerido y, si no lo tuviera ya en territorio nacional, el de su última residencia en España (art. 140.1 LJV). Se fija un tope cuantitativo en $6.000 €$, de tal forma que si el importe de la petición fuera inferior al mismo y no se tratara de cuestiones propias de los Juzgados de lo Mercantil, el conocimiento del acto de conciliación corresponda al Juez de Paz -cfr. art. 47 de la Ley de Enjuiciamiento Civil, LEC-. Si el requerido fuera una persona jurídica se produce una inversión, resultando competente el letrado de la Administración de Justicia o Juez de Paz del lugar del domicilio del solicitante "siempre que en dicho lugar tenga el requerido delegación, sucursal, establecimiento u oficina abierta al público o representante autorizado para actuar en nombre de la entidad, debiendo acreditar dicha circunstancia".

Quien inste este acto habrá de presentar ante el órgano competente solicitud por escrito. No es preceptiva la intervención de abogado ni procurador ni, por ende, se exige ninguna clase de fundamentación jurídica en la solicitud (art. 141 LJV).

La autoridad competente dictará resolución sobre la admisión de la solicitud y citará a los interesados, señalando día y hora en que el acto deba tener lugar. La presentación seguida de admisión de la solicitud produce efectos procesales concretos: interrumpe la prescripción desde el momento de la presentación; pero ese plazo volverá a computar desde que recaiga decreto del letrado de la Administración de Justicia o auto del Juez de Paz poniendo término al expediente (art. 143 LJV).

La comparecencia de las partes al acto de conciliación deberá producirse por sí mismas "o por medio de procurador". Si no compareciera el solicitante ni alegara justa causa para no concurrir "se le tendrá por desistido y se archivará" el expediente. Si fuera el requerido de conciliación quien no compareciera ni aportara justa causa para no concurrir, se pondrá fin al acto teniendo la conciliación por intentada a todos los efectos legales. Si los requeridos fueran varios y concurriera solamente alguno de ellos, se celebrará el acto con los comparecidos y se tendrá por intentada la conciliación respecto a los no comparecidos.

El art. 145 LJV regula la celebración del acto de conciliación. El solicitante expondrá su reclamación y los fundamentos en que la respalde, contestando seguidamente el requerido. El Juez de Paz o el letrado de la Administración de Justicia "procurará avenirlos, permitiéndoles replicar y contrarreplicar, si quisieren y ello pudiere facilitar el acuerdo", con lo que se comprueba que la posición de este tercero no invade el ámbito conceptualmente propio de la mediación -supra-. Si hubiera conformidad entre los interesados en todo o en parte del objeto de la conciliación, se hará constar detalladamente en acta todo cuanto acuerden y que el acto terminó con avenencia, así como sus términos. Si no pudiere alcanzarse acuerdo alguno, se hará constar que el acto concluyó sin avenencia. El art. 145.4 LJV añade que finalizado el acto el letrado de la Administración de Justicia o el Juez de Paz dictarán decreto o auto, respectivamente, constatando la avenencia o, en su caso, que se intentó sin efecto o se celebró sin avenencia, "acordándose el archivo definitivo de las actuaciones".

La suma del testimonio del acta y del decreto o auto dictado reflejando la avenencia de las partes en el acto de conciliación llevará aparejada ejecución, teniendo lo acordado valor y eficacia de un convenio consignado en documento público y solemne (art. 147.1 LJV), a los efectos previstos por el art. 517.2.9ํㄴ.

\section{b) Mediación}

Por mediación, siguiendo a MARTíN DIZ, se aludirá a "un sistema de resolución de conflictos, en el cual un tercero se interpone entre los contendientes procurando su reconciliación mediante su asistencia en la obtención de un acuerdo"19. No se refiere, aunque comparta denominación, a "la actividad empresarial de quienes se dedican profesional y habitualmente al ejercicio de actividades de mediación en la venta y organización de servicios, con posibilidad de que utilicen medios propios para llevarlas a cabo"20.

Genéricamente, hemos de aludir a la regulación que se encuentra actualmente en la Ley 5/2012, de 6 de julio, de Mediación en asuntos civiles y mercantiles (LM, en lo sucesivo). En la LM se subraya su utilidad en su ámbito material propio, esto es, derechos subjetivos de carácter disponible y, además, que su generalización permitiría

${ }^{18}$ Vid. MARTíNEZ DE SANTOS, 2016. "El acto de conciliación en la nueva Ley de Jurisdicción Voluntaria", Diario La Ley, $\mathrm{n}^{\circ}$ 8699, de 10 de febrero.

19 MARTÍN DIZ, 2010: 50. "La mediación, sistema complementario de Administración de Justicia”, CGPJ, Madrid.

${ }^{20}$ RAMALLO MILLÁN, 2013: 65. “Manual básico...”, cit. 
concebir a la Jurisdicción como último remedio, coadyuvando así a su deseable reducción de carga de trabajo. Ahora bien, su radio de acción normativo se circunscribe al ámbito de competencias estatales en materia de legislación civil y mercantil, sin perjuicio pues de lo que regularan las Comunidades autónomas en sus respectivos marcos competenciales.

El modelo legal se basa en la voluntariedad y libre decisión de las partes, junto a la intervención de un mediador caracterizado por una actitud activa en aras de la solución de la controversia surgida, la cual siempre está a cargo de las propias partes, con independencia del nombre que se otorgue a este instrumento (art. 1 LM). Por tanto, la normación se impregna de clara flexibilidad que sirva de acicate para su mayor utilización, poniendo el foco más en el principio dispositivo (que también preside el ámbito del conflicto nacido) que en la abstracta formulación de las leyes.

El eje medular de la LM radica en el mediador, en tanto agente que ayude a hallar una solución dialogada y querida por las partes. Ello acarrea indefectiblemente que deba gozar de la formación suficiente y adecuada para desempeñar con rigor y solvencia este papel, con plena garantía para quienes a él acuden. En concreto, los principios informadores de la mediación resultan ser: voluntariedad, igualdad de oportunidades de las partes, imparcialidad de los mediadores, neutralidad y confidencialidad (arts. 6 a 9 LM).

Las partes sujetas voluntariamente a mediación actuarán entre sí conforme a los principios de lealtad, buena fe y respeto mutuo, debiendo también prestar colaboración y apoyo permanente a la actuación del mediador, manteniendo la adecuada deferencia hacia su actividad (art. 10 LM). El mediador facilitará la comunicación entre las partes, velando porque dispongan de la información y asesoramiento suficientes. Además, "desarrollará una conducta activa tendente a lograr el acercamiento entre las partes" dentro de los principios arquitecturales de la LM (art. 13.2).

El procedimiento de mediación atraviesa por estas fases principales: solicitud de inicio (de común acuerdo por las partes o por una de las partes en cumplimiento de un preexistente pacto de sometimiento a mediación), citación por el mediador propuesto o designado para una sesión informativa de éste a las partes (características de la mediación, circunstancias profesionales del mediador, procedimiento, consecuencias jurídicas de un eventual acuerdo...), sesión constitutiva, ulteriores sesiones (intentando concentrarlas para que resulte el menor número posible de ellas) y terminación (con acuerdo o sin alcanzarlo -por exceso de plazo prefijado, irreconciliabilidad de las posiciones de las partes, concurrencia de causas que así lo determinen...-) a reflejar en acta.

De llegarse a un acuerdo, podrá versar sobre una parte o sobre la totalidad de las materias sometidas a mediación (art. 23.1 LM).

Las partes podrán elevar a escritura pública el acuerdo alcanzado tras el seguimiento de un procedimiento de mediación (art. 25.1 LM). Ese acuerdo ostenta condición de título ejecutivo cara a su eventual cumplimiento por conducto judicial.

De todas formas, visto el esquema del modelo legal, conceptual y procedimentalmente, hay que destacar una previsión capital a los fines que se persiguen en este trabajo. Ex art. 2.2 d) LM "quedan excluidos, en todo caso, del ámbito de aplicación de esta Ley (...) la mediación en materia de consumo".

\subsection{Mecanismos heterocompositivos}

En este caso, nos encontramos básicamente con dos instituciones: el arbitraje y la Jurisdicción.

\section{a) Arbitraje}

Por arbitraje entendemos el procedimiento por el que se somete una controversia, por acuerdo de las partes, a un árbitro o a un tribunal de varios árbitros que dictan una decisión obligatoria para tales partes sobre ella. Se trata de un procedimiento privado de solución de conflictos, frente a la Jurisdicción que se inserta indudablemente en la arquitectura pública estatal. Asimismo, está presidido por un criterio antiformalista, antónimo al imperante en el ámbito de la Jurisdicción.

Su regulación genérica en nuestro Derecho nos la ofrece actualmente la Ley 60/2003, de 23 de diciembre, de Arbitraje (LAr), la cual es de aplicación supletoria a los arbitrajes previstos por otras normas jurídicas del Ordenamiento español (reténgase). Su art. 2 preceptúa que son susceptibles de arbitraje "las controversias sobre materias de libre disposición conforme a Derecho", gozando las partes de amplias facultades de ordenación y decisión. En los asuntos regidos por la LAr no intervendrá ningún órgano judicial, salvo en los casos en que se dispusiera ope legis (art. 7).

El convenio arbitral, que habrá de constar por escrito, podrá adoptar la forma de cláusula incorporada a un contrato o la de acuerdo independiente, debiendo expresar la voluntad de las partes de someter a arbitraje todas o algunas de las controversias que hayan surgido o puedan surgir respecto de una determinada relación jurídica, 
contractual o no contractual. Si el convenio estuviera contenido en un contrato de adhesión, su validez e interpretación se regirá por las normas específicas aplicables a esa modalidad de contrato (art. 9 LAr). En cualquier caso, el convenio arbitral obliga a las partes a cumplir lo establecido e impide a los Tribunales conocer de las controversias sometidas a arbitraje, "siempre que la parte a quien interese lo invoque mediante declinatoria", la cual no impedirá la iniciación o prosecución de las actuaciones arbitrales (art. 11 LAr).

En cuanto a la figura del árbitro, las partes podrán fijar libremente su número siempre que sea impar. A falta de acuerdo, se nombrará uno solo (art. $12 \mathrm{LAr}$ ). Su actuación habrá de hallarse regida por los principios de igualdad, audiencia y contradicción ex art. 24 LAr.

Las partes también gozan del derecho de convenir libremente el procedimiento al que los árbitros hayan de ajustar sus actuaciones. En defecto de acuerdo, los árbitros podrán dirigir el arbitraje del modo que consideren apropiado, aunque siempre con sujeción a las previsiones de la LAr. Esta potestad de los árbitros comprende "la de decidir sobre la admisibilidad, pertinencia y utilidad de las pruebas, sobre su práctica, incluso de oficio, y sobre su valoración" (art. 25 LAr).

Los árbitros decidirán conforme a normas jurídicas. Podrán hacerlo en equidad solamente si las partes les han autorizado expresamente para ello. Si las partes no indicaran las normas aplicables, los árbitros acudirán a "las que estimen apropiadas. En todo caso (...) decidirán con arreglo a las estipulaciones del contrato y tendrán en cuenta los usos aplicables" (art. 34 LAr).

La decisión final adoptada por los árbitros adopta forma de laudo, que deberá constar por escrito. Habrá de ser siempre motivado y podrá ser protocolizado notarialmente. Es preciso subrayar que el laudo produce efecto de cosa juzgada (art. 43 LAr), constituyendo título ejecutivo a los efectos previstos en la LEC.

\section{b) La Jurisdicción}

En nuestro Ordenamiento jurídico existe un sólido paradigma constitucional de Juez que tiene que regir en el despliegue de la función jurisdiccional, que se orientará teleológicamente a la consecución de una integral protección de los derechos que, a la par, permita el vigor de la justicia en cuanto valor material inspirador de nuestro Ordenamiento jurídico (art. 1.1 CE). El peculiar y reforzado estatuto del Juez sirve para erigirlo en una garantía de imperio de la legalidad erga omnes. El Juez pasa a constituir por volición constitucional un poder público conceptuable como un caracterizado órgano de Derecho. El Juez es un cualificado servidor de los derechos de "todas las personas" -art. 24.1 CE-.

Siendo el Juez un garante primario de los derechos de la ciudadanía, nace un compromiso juridificado ope CE para el cumplimiento del derecho a la tutela judicial efectiva, eje vertebrador a través del cual se da acceso a todos los demás derechos subjetivos susceptibles de esta fiscalizadora supervisión. La función jurisdiccional es así la exteriorización estatal que más intensamente se cose a los derechos fundamentales y, por tanto, enlaza con la constitucionalidad que es la sede en la que aquéllos residen.

En un trazo esquemático, la función jurisdiccional no consiste más que en la realización efectiva del orden jurídico, juzgando y haciendo ejecutar lo juzgado a través de Jueces y Tribunales independientes, inamovibles, responsables y sometidos únicamente al imperio de la ley (art. $117.1 \mathrm{CE})^{21}$. Semejante actividad se concreta a través del examen y resolución de dispares pretensiones de parte, volcadas en el seguimiento de un curso procesal legislativamente predeterminado, en orden a reparar bien una lesión en ese orden jurídico, bien declarando qué es o no acorde a Derecho. El Juez tiene obligación constitucionalmente impuesta de conocer toda pretensión que se le presente siguiendo un proceso legalmente prefigurado. La Jurisdicción tutela y actúa el Derecho objetivo sin que la resolución de controversias erija su única finalidad, sino una consecuencia más de esa labor. En ella lo que se aplica no es la voluntad de las partes, sino la ley, la "solución jurídica que corresponde dar" a un supuesto planteado ${ }^{22}$, a donde solamente puede llegarse tras el seguimiento del proceso.

La CE incluye en su articulado un elenco de derechos que se califican como fundamentales (Sección primera, Capítulo segundo, Título primero). Dentro del listado de esos derechos fundamentales, el art. 24.1 CE recoge el derecho a la tutela judicial efectiva adornado con las notas de irrenunciabilidad e indisponibilidad.

Su contenido es muy complejo, proyectado en distintos aspectos a sistematizar con un criterio eminentemente cronológico mediante una cadencia ordenada y sucesiva de hitos, desde el acceso mismo a la Jurisdicción hasta la final ejecución de la resolución adoptada judicialmente en cada supuesto específico (cfr. STC 220/1993, de 30

${ }^{21}$ CRUZ VILLALÓN, 2003: 34. "El Juez como garante de los derechos fundamentales", en la obra "Constitución y Poder Judicial, XXV aniversario de la Constitución de 1978 (...) La función jurisdiccional es el poder del Estado que con mayor intensidad (...) se encuentra configurado en términos de derechos fundamentales (...) Se trata del Poder del Estado en el que antes, y con mucha diferencia, las cuestiones de legalidad se convierten en cuestiones de constitucionalidad; o en el que la proporción relativa de legalidad y constitucionalidad más claramente se vence a favor de esta última", CGPJ, Madrid.

22 HERRERO PEREZAGUA, 2014: 17. "Lo jurisdiccional en entredicho", Thomson Reuters-Aranzadi, Pamplona. 
de junio). Desgranándolo, DíEZ-PICAZO23 obtiene cuatro bloques: el derecho de acceso a la Jurisdicción, o derecho a la tutela judicial efectiva stricto sensu; el derecho al Juez ordinario predeterminado por la Ley; las garantías constitucionales genéricas de todo proceso (proceso debido); y las garantías constitucionales específicas del proceso penal.

Existe así un derecho subjetivo a la salvaguarda jurisdiccional de otros derechos subjetivos, a quienes cobija y asevera. En cuanto derecho fundamental, la tutela judicial efectiva goza de un contenido esencial indisponible al legislador ordinario (art. 53.1 CE); pero también se trata de un derecho prestacional de amplia configuración legal, fruto de la acción legislativa de cada momento. No constituye un derecho ejercitable sin más, exigiendo para ello perentoriamente la interpositio legislatoris (cfr. STC 112/1997, de 3 de junio). Cabe ese ejercicio, pero siguiendo los cauces que el legislador establece (STC 17/2011, de 3 de mayo).

El derecho fundamental a la tutela judicial efectiva se plasma en el ejercicio de las correlativas acciones, las cuales únicamente se canalizan o instrumentan a través del proceso. La acción y el proceso se funden para la consecución final de una tutela judicial y efectiva, en los cánones queridos por el art. $24.1 \mathrm{CE}^{24}$. En suma, es la Jurisdicción a través del proceso "el lugar en que se ofrece el último y supremo cauce para su defensa, versando toda la actuación jurisdiccional solo sobre el derecho que no ha sido observado"25, un último reducto de tal relevancia que se positiviza en la CE.

La conclusión a obtener es evidente: el modelo que prevea la legislación procesal en cada momento es clave para determinar el ejercicio y vehiculización de este derecho fundamental. En nuestro caso, desde el Derecho Privado, ese criterio paradigmático rector nos lo brindará la LEC ${ }^{26}$.

\section{SU EFECTIVIDAD Y EFICACIA PROYECTADA AL ÁMBITO DEL DERECHO DEL TURISMO. VALORACIÓN CRÍTICA}

Vamos ahora a proyectar lo expuesto al concreto campo del turismo. Seguiremos la misma sistemática expositiva.

\subsection{Mecanismos autocompositivos}

Conforme hemos apuntado, en ellos cabe integrar a la conciliación y la mediación.

\section{a) La conciliación}

Ciertamente, pueden detectarse algunas dificultades ligadas al paradigma legislativo seleccionado para atribuir competencia de conocimiento a los distintos órganos jurisdiccionales con capacidad para tramitar y resolver estos expedientes, en función del objeto concreto de conciliación que se proponga (Juzgado de Primera Instancia -en su caso, de Paz- o de lo Mercantil, supra).

Podría existir la ventaja evidente, caso de que esa relación jurídica se hubiera entablado entre turista y un empresario turístico con forma de persona jurídica, consistente en que el órgano judicial competente fuera el de domicilio o residencia del conciliante, si el conciliado tuviera en esa localidad "delegación, sucursal, establecimiento u oficina abierta al público, o representante autorizado para actuar en nombre de la entidad" (art. 140.1 LJV).

Asimismo, estimamos inicialmente positivo para el turista la no preceptiva postulación; si bien hay que recordar que la comparecencia al acto de conciliación habrá de realizarse por el propio conciliante, pues de no ser así sí

\footnotetext{
${ }^{23}$ DÍEZ-PICAZO, 2004: 364. "Sistema de derechos fundamentales", Civitas, Madrid.

${ }^{24}$ CALAZA LÓPEZ, 2011: 44. "La acción (...) tan solo se despierta (...) procesalmente, en su posición activa, o se resiste, en su posición pasiva, bien cuando se ha producido un conflicto intersubjetivo o social o bien cuando, sin necesidad de esta controversia previa, una determinada situación jurídica requiere o precisa una concreta tutela judicial (...) la acción sólo se materializa o instrumenta (...) a través del proceso", por lo que "el proceso es el instrumento de la acción. La acción abarca momentos que alcanzan periodos de tiempo anteriores, presentes y posteriores al proceso (...) Ahora bien, la acción (...) no tiene más realidad que la que el proceso le otorga (...) La acción sin proceso es meramente virtual, una acción en potencia". En fin, "el objeto del proceso (...) no lo constituye la acción (...) sino la pretensión (...) sea activa (...) o pasiva (...) La pretensión no es un derecho subjetivo sino una mera petición, efectuada ante el órgano judicial, ya sea desde el lado activo (...) ya desde el pasivo (...) con vistas a que éste responda, por el cauce o vía del proceso, de manera motivada, congruente y estable". " $E$ l binomio procesal: derecho de acción-derecho de defensa, desde la concepción clásica romana hasta la actualidad", Dykinson, Madrid.
}

${ }^{25}$ BONET NAVARRO, 2015: 31. “La experiencia procesal del fracaso del Derecho", Universidad de Zaragoza.

${ }^{26}$ Cfr. BARONA VILAR, 2002. "Tutela de los consumidores y usuarios en la Nueva Ley de Enjuiciamiento Civip", Tirant lo Blanch, Valencia. 
debería apoderar procurador para ello (arts. 141.3 y $144.1 \mathrm{LJV}$, de consuno). Pero hemos de valorar qué tipo de conflictos podemos encarar en estos supuestos. Su nacimiento se va a producir en el seno de relaciones jurídicas eminentemente complejas, de contenido técnico-jurídico innegable. ¿Cabe esperar que verdaderamente un turista por sí mismo articule correctamente, sin asistencia letrada, la petición que encauce por vía de la conciliación? Item más, si eventualmente se alcanzara un acuerdo que finiquitara el conflicto nacido y fuera preciso instar su ejecución forzosa, el art. 147 LJV nos remite al procedimiento de ejecución prevenido por la LEC, léase plenamente judicial, en el que la postulación ya podría ser preceptiva a la vista conjunta del tenor de los arts. 23 y 31 LEC interpretados en sentido contrario.

Por consiguiente, creemos que su utilidad y efectividad para aplicación al ámbito de las relaciones jurídicas trabadas en el sector turístico no resulta integral. Entendemos particularmente que cabe razonablemente esperar que las complejidades insitas a esta clase de relaciones jurídicas sean capaces de menoscabar la plena viabilidad de este instrumento para cubrir eficientemente la posición jurídica del turista en todos los supuestos. Si va a resultarle conveniente servirse de asistencia profesional, más allá de conseguir algunos concretos efectos propiamente procesales (interrupción de plazos de prescripción, art. $143 \mathrm{LJV}$ ), quizás sea más efectivo utilizar otro tipo de herramientas para asegurar y proteger al turista víctima de un incumplimiento o necesitado del cumplimiento forzoso de las obligaciones de las que es acreedor.

A ello habrá que añadir la incidencia de otros obstáculos en orden a la propia desigual posición de las partes en conflicto y la naturaleza no disponible de mucha normativa aplicable a las relaciones jurídicas en liza, que por evitar duplicidades abordamos en el siguiente apartado.

\section{b) La mediación}

El régimen jurídico contenido en la LM no puede ser aplicable tal cual al giro turístico por erigir una especie de la que se rotula como "mediación en materia de consumo", quien queda expresamente excluida de su ámbito de aplicación ex art. 2.2 d) LM. Ahora bien, ello no conlleva que estos sectores queden vetados a la susceptibilidad de ser objeto de mediación, sino que se obra así "para reservar su regulación a las normas sectoriales correspondientes" -apartado II in fine del Preámbulo de la LM-.

RALUCA STROIE 27 apunta tres motivos por los cuales las relaciones de consumo quedan fuera de la LM: (1) Hallarnos ante una materia sujeta a legislación de carácter imperativo, esto es, derechos y obligaciones no disponibles a las partes, luego ajenas a alteración basada en su voluntad (2) Observar relaciones jurídicas asimétricas, donde el consumidor/turista ostenta una posición jurídica y económica sensiblemente más débil que la del empresario turístico (3) Erigir una materia cuya regulación es competencia de las Comunidades autónomas (supra).

Aun en caso de afrontar una mediación en este terreno, nos encontraríamos con otras dificultades operativas que cuestionarían severamente su final éxito. Pensemos, por ejemplo, en que sería necesario dotar a los mediadores de una acreditada formación específica en la materia, especialmente en su faz jurídica lo cual, habida cuenta la dispersión normativa que ya hemos constatado, no será sencillo.

Bien, considerando los factores expresados y la disposición excluyente de la LM, ponemos en solfa la viabilidad misma de un sistema de mediación aplicable al ámbito turístico, tal cual académicamente ha de entenderse. Es dudoso aceptar el sometimiento a mediación de las controversias nacidas a raíz de las relaciones jurídicoturísticas dado que su génesis no arranca de una igualdad de partes que permita una disposición plena de los derechos y obligaciones gestados y convertidos en conflictivos. La mediación en este sector pierde sentido desde el momento en que ha ganado sustantividad desagregada de un proceso arbitral en donde simplemente consiste en una etapa previa que permita eximir, en su defecto, el dictado de un laudo -infra-. Pero la negociación es compleja, cuando no realmente difícil, si hay disparidad de las posiciones de parte, desequilibrio económico, clausulado predispuesto...

Por lo tanto, la comprobada existencia de problemas etiológicos en el acoplamiento de los principios generales de la mediación a los particularismos del turismo nos conduce a pensar en una escasa viabilidad de esta técnica para superar los conflictos propios de este giro.

\subsection{Mecanismos heterocompositivos}

En este epígrafe, debemos observar el arbitraje y la Jurisdicción.

\footnotetext{
${ }^{27}$ RALUCA STROIE: “¿Es viable un modelo de mediación de consumo autónomo desde el punto de vista de las materias que puedan ser objeto de mediación?', Centro de Estudios de Consumo, Universidad de Castilla-La Mancha, disponible on line.
} 


\section{a) Arbitraje}

Engarzado al esquema genérico de la LAr y sus rasgos definitorios, en el ámbito turístico deberíamos gozar de normación específica. Pero la reglamentación sin carácter singularizado ratione materiae se plasma en el Real Decreto 231/2008, de 15 de febrero (RDAC) ${ }^{28}$, en tanto "arbitraje institucional de resolución extrajudicial, de carácter vinculante y ejecutivo para ambas partes, de los conflictos surgidos entre los consumidores o usuarios y las empresas o profesionales en relación a los derechos legal o contractualmente reconocidos al consumidor" (art. 2 RDAC).

$\mathrm{Si}$ el turista es un consumidor, le resulta aplicable de lleno esta regulación (art. 3.2 RDAC) que procedimentalmente resulta muy sencilla (arts. 33 y ss. RDAC). Cuando el consumidor/turista entienda que se han vulnerado sus derechos en el curso de relaciones jurídico-privadas integradas en el tráfico turístico, puede solicitarlo tanto si el empresario se halla previamente adherido a arbitraje cuanto si llega a aceptarlo en el supuesto conflictual surgido. El arbitraje de consumo se decidirá en equidad, salvo que las partes opten expresamente por la decisión en Derecho, pero las normas jurídicas aplicables y las estipulaciones del contrato servirán de apoyo a la decisión en equidad que, en todo caso, deberá ser motivada (art. 33 RDAC).

El Sistema Arbitral de Consumo se organiza a través de las Juntas Arbitrales de Consumo, la Comisión de las Juntas Arbitrales de Consumo, el Consejo General del Sistema Arbitral de Consumo y los órganos arbitrales (art. 4 RDAC).

El procedimiento arbitral de consumo se ajustará a los principios de audiencia, contradicción, igualdad entre las partes y gratuidad, así como por la confidencialidad (art. 41.1 RDAC). Comienza por solicitud, que habrá de reunir los requisitos del art. 34 RDAC y no comprenden la fundamentación jurídica. El órgano arbitral dirigirá el procedimiento con sujeción a lo dispuesto en esta norma, pudiendo instar a las partes a la "conciliación" (art. 42.1 RDAC). Conforme al art. 38 RDAC, cuando no existan causas de inadmisión de la solicitud de arbitraje se intentará "mediar" para que las partes alcancen un acuerdo que ponga fin al conflicto, salvo oposición expresa de cualquiera de las partes o cuando conste que la mediación ha sido intentada sin efecto. La mediación se regirá por la legislación sobre la materia que resulte de aplicación. En la prosecución del procedimiento, existen trámites de audiencia y prueba.

Este arbitraje culminará mediante laudo, motivado en todo caso, con reenvío expreso a la LAr (art. 48 RDAC), con igual valor y efectos que el allí previsto.

El texto del RDAC contiene disposiciones especiales en relación al arbitraje de consumo electrónico y al arbitraje de consumo colectivo, pero no hace ninguna mención al sector del turismo. Por tanto, sin perjuicio de poder utilizar esta vía sin mayores complicaciones, se propugna la regulación de un arbitraje propio del ámbito turístico que llegue a disfrutar de sistematización debidamente particularizada. Lege ferenda sería muy provechoso promulgar normativa en ese sentido sin tener que encajar prevenciones globales en las singularidades de este giro: árbitros especializados, una estructura administrativa igualmente ajustada y conocedora en profundidad de estos temas (que dentro de lo turístico poseen diversas vertientes por su intrínseca multidisciplinariedad), aseguramiento del plurilingüismo para cubrir las necesidades del turista extranjero que acudiera a este instrumento en España, un diseño procedimental aún más simplificado que, con plenas garantías, colme la máxima celeridad (pensemos $v$. gr. en un turista extranjero que retorna a su país tras su estancia turística. Sería deseable que estos avatares pudieran ser resueltos durante su estancia en nuestro territorio), etc. El volumen de la actividad turística parece argumento suficiente para normar esta sectorial especialización material.

\section{b) Jurisdicción}

En este caso, el protagonismo ha de residir en la LEC, como ya hemos razonado anteriormente. Pero buceando en su articulado, el fenómeno turístico no hace acto de presencia ni como tal ni con referencia al turista.

Sí hay menciones a los consumidores como colectivo, una de cuyas personificaciones es el turista. Pero según se señala en la Exposición de motivos de la LEC, la alusión se hace a modo de "respuesta tributaria e instrumental de lo que disponen y puedan disponer en el futuro las normas sustantivas acerca del punto, controvertido y difícil, de la concreta tutela que, a través de las aludidas entidades, se quiera otorgar a los derechos e intereses de los consumidores y usuarios en cuanto colectividades. Como cauce para esa tutela, no se considera necesario un proceso o procedimiento especial -nótese el posicionamiento del legislador- y sí, en cambio, una serie de normas especiales, en los lugares oportunos" (apartado VII). En atención a este principio, los arts. 6.1, 11 y 15 LEC conceden a esas colectividades capacidad para ser parte en un proceso civil. También se prevén otras modulaciones dispersas en el articulado de la esta Norma procesal: invalidez de pactos de sumisión expresa territorial contenidos en contratos de adhesión celebrados con consumidores (art. 54.2),

${ }^{28}$ Con carácter general sobre esta norma, DÍAZ ALABART, 2005: 1285-1302. "El arbitraje de consumo y la nueva Ley de Arbitraje", Revista Actualidad Civil, n 1, Madrid; o BONACHERA VILLEGAS 2008. "El Real Decreto 231/2008, la anhelada modificación del sistema arbitral de consumo", Diario La Ley, $\mathrm{n}^{\circ} 7045$, de 30 de octubre. 
acumulaciones de procesos (art. 76.2.1ํ), especialidades en las sentencias dictadas en procesos promovidos por asociaciones de consumidores o usuarios (art. 241), o la acción ejecutiva de consumidores y usuarios fundada en sentencia de condena sin determinación individual de los beneficiados (art. 519).

Pero subráyese que esas previsiones se centran básicamente en presupuestos procesales en lugar de prestar regulación singular o particular ratione materiae valorando factores intrínsecos al fenómeno turístico en los que venimos haciendo hincapié. Únicamente dentro del proceso monitorio contamos con el tenor del art. 815.4 LEC, aunque de su lectura se desprende más bien que es un supuesto pensado para los casos en que el demandante sea el empresario. Por tanto, los mecanismos concretos para la protección y defensa de derechos del turista serán los comunes: juicio declarativo (previsiblemente el juicio verbal dado que las cuantías objeto de reclamación tenderán a ser generalmente inferiores a $6.000 €$, art. 248.2 LEC) y, de ser preciso, ejecución (arts. 549 y ss. LEC). La asistencia de abogado y procurador sería preceptiva por encima de los $2.000 €$ de reclamación (arts. 23 y 31 LEC). Los trámites procesales llevarán sus tiempos, los eventuales recursos dilatarán más el curso del procedimiento....

Este conjunto de incidencias hace poco atractivo acudir a esta vía, lo cual no desmerece su relevancia ni su posición como último y supremo bastión de los derechos y obligaciones subjetivos: duración excesiva de los procedimientos, desproporción entre el objeto de la demanda y el coste del proceso, la complejidad técnica del proceso que hace conveniente la asistencia letrada si no fuera preceptiva, el formalismo imperante en cuanto innegable garantía de respeto a la legalidad procesal...

Debiendo existir y personificada en un derecho fundamental, ¿es la Jurisdicción verdaderamente eficiente para suturar los conflictos surgidos en el giro turístico? Siendo una garantía indudable y ejecutiva para el turista, ¿es capaz de brindar su tutela de forma ágil y sencilla, acorde al tipo de relaciones jurídicas conflictivas a las que nos estamos ciñendo? Precisamente por los factores anteriormente glosados y por la carencia de procedimientos específicos para atender las eventuales demandas en este ámbito, creemos que se corre un notable riesgo de ineficaz colapso de esta garantía. En efecto, partimos de una regulación sustantiva disforme y dispersa -primer reto -. Pero si a ello le agregamos que el marco del proceso no se ajusta pacíficamente a esas particularidades, entendemos que el paradigma reinante puede abocar al fracaso del derecho subjetivo, espoleado por el inevitable peso del proceso.

Por eso, desde la irrenunciabilidad que porta en sí la Jurisdicción, se considera perentoria la inserción de algunas técnicas concretas, procesales, que cierren esas oquedades por las que puede precipitarse la consecución de una tutela judicial realmente efectiva y eficaz en el sector turístico.

\section{ALGUNAS IDEAS FINALES}

Dejaremos indicadas algunas ideas a modo de áreas en las que insistir para lograr una mejoría y fortalecimiento en el sistema de protección jurídico-privada español de la posición del turista.

\section{l.- Aspiración a la homogeneización del régimen jurídico del turismo}

Resulta del todo incomprensible que, habida cuenta la relevancia económica que para el Estado tiene el turismo, contemos con diecisiete regímenes distintos. Es un flagrante error su concepción como una competencia exclusivamente autonómica. Apegarse a una visión cuasi medieval presidida por una atomizada fragmentación para regular una actividad económica tan universal y supralocal es un paradójico sinsentido, dado que mientras existe normativa comunitaria tendente a la unificación legislativa en todos los Estados miembros, España actúa internamente en sentido frontalmente opuesto. Una saturación normativa no armónica no puede ser positiva para el turismo.

Argumentación jurídica para subsanar esta gruesa deficiencia existe. Se atribuye a la normación autonómica esta materia en base a la dispar situación turística de cada territorio del Estado, pero eso no puede abortar una precisa coordinación. Sin perjuicio de lo previsto por el art. 148.1.18, el art. 149.1.13 CE atribuye al Estado competencia exclusiva en lo que atañe a la planificación general de la actividad económica. Y resulta evidente que el sector turístico participa como punta de lanza de ese rasgo. Otro tanto puede suceder respecto a la competencia estatal de "comercio exterior", art. 149.1.10 CE. Una ley estatal básica en la materia aclararía la insufrible disformidad normativa que, por supuesto, es plenamente lesiva para la esperable seguridad jurídica que consagra el art. 9.3 CE.

Esta carencia no afecta solamente al ámbito del Derecho Público, pues allí donde las Comunidades autónomas regulan cuestiones propias de este sector académico, en una suerte de extralimitación silente u oblicua hacia el Derecho Privado, tienden a reglar otros lares que, pareciendo falsamente conexos y sobre los que ya dudosamente gozarían de capacidades normativas, se adentran en otros aspectos como, por ejemplo, el régimen de ciertos elementos de los contratos a cuya virtud se constituyen aprovechamientos turísticos a tiempo compartido. 


\section{II.- Necesidad de arbitrar mecanismos que superen la eventual inconsistencia e insuficiencia del sistema de garantías para el turista en nuestro Ordenamiento interno}

Las dificultades detectadas en el conjunto normativo regulador del fenómeno turístico tienen a nuestro entender perfecto trasunto a la hora de arbitrar mecanismos de defensa para el turista.

a) Estimamos que la conciliación no se ajusta bien a la materia del turismo. Sin perjuicio de sus ventajas, antiformalismo, gratuidad... el tipo de conflictos que se conocen son complejos, y la efectividad de un acuerdo puede quedar condicionada a un procedimiento de ejecución plenamente judicial. Solamente se podría ahorrar tiempo, de haber avenencia, evitando un proceso judicial declarativo. Pero aun así no parece que la conciliación suponga un remedio integral para suturar conflictos de esta índole. Y ello sin olvidar que tal vez no quepa transigir sobre muchos aspectos apegados al turismo por estar presididos por regulaciones de ius cogens.

b) La mediación no constituye una herramienta útil para este concreto sector. Si gran parte de las normas del Derecho del Turismo son de carácter imperativo, las posibilidades de negociación sobre ellas de las partes enfrentadas están impedidas ope legis. Por tanto, la figura del mediador se desdibuja si el potencial acuerdo no nace de la voluntad de las partes, sino que queda pautado unívocamente por la ley. Un uso incondicional de esta institución generaría un alto riesgo de consagrar la objetiva desigualdad entre turista y empresario, expresamente prohibida.

c) El arbitraje adolece de problemas estructurales que también lo alejan de la deseable eficacia para encarar el fenómeno turístico. Este giro tiene su especificidad comprensiva de una tangible heterogeneidad en sus servicios propios donde nacerán esos litigios, y ha de lograrse una cualificada agilidad a pesar de muchas dificultades que no concurren en otros ámbitos del consumo (idioma, rapidez de tiempo de prestación de los servicios conflictivos, cuantía limitada de las reclamaciones, redundancia en la imagen de todo el país...). Entonces, es preciso acometer la creación de un sistema de Arbitraje de turismo especial y nacional que, a la par, sugiera al turista sensación de solvencia y seriedad aun como mera potencialidad que le ofrezca el empresario turístico. Entre tanto ello suceda, el arbitraje de consumo con el que contamos actualmente erige una solución parcial, con aspectos poco amoldables al turismo.

d) La Jurisdicción es la última fortaleza para la defensa de todos los derechos, también los que puedan verse lesionados en el giro turístico. Incardinado al género jurídico de consumidor, el turista goza de previsiones favorables en la LEC. Pero no hay una previsión procesal que, atendiendo materialmente a esta clase de conflictos, prime la celeridad o rapidez, el antiformalismo, que lime la dificultad técnico-jurídica del proceso... Por lo tanto, valorando el tipo de pretensiones que se ejercitan y las circunstancias que las orbitan, seguramente este sendero no sea especialmente atractivo para el turista necesitado de esa tutela de sus derechos.

En suma, a nuestro juicio no podemos predicar del actual Ordenamiento jurídico privado español la existencia de mecanismos radicalmente específicos y aptos para dotar al turista de garantías plenamente ágiles, particulares y eficientes en caso de infracción de sus derechos. Su importancia cualitativa, la singularidad de las relaciones jurídicas que ampara el turismo... hacen preciso afinar esos mecanismos.

No se corresponde la relevancia de este fenómeno con lo difuminadas e ineficaces que parecen las previsiones arbitradas (o ni tan siquiera implementadas) para garantizar la superación de conflictos en su seno surgidos. $Y$ solamente desde una solvente fortaleza de esos instrumentos una experiencia negativa del turista puede ser restañada, evitando que esa percepción peyorativa se duplique, en su consumación y en una ulterior deficiente reparación.

Va en ello la calidad misma del sistema, quizás derrotada por la endeblez de su inadecuada normación. Y no podemos permitirnos que esto suceda, sobre todo en las técnicas heterocompositivas visto que las autocompositivas pueden hallarse lastradas por el imperio de abundantes normas de ius cogens.

\section{BIBLIOGRAFÍA}

AA.VV (2003): "Constitución y Poder Judicial, XXV aniversario de la Constitución de 1978”, CGPJ, Madrid.

BARBA DE VEGA, J. y CALZADA CONDE, Á. (2004): “Introducción al Derecho Privado del Turismo", ThomsonAranzadi, Pamplona.

BARONA VILAR, S. (2002): "Tutela de los consumidores y usuarios en la Nueva Ley de Enjuiciamiento Civil", Tirant lo Blanch, Valencia.

BAUZÁ MARTORELL, F. J. (2014): "Hacia una legislación básica en materia de turismo. A propósito de las centrales electrónicas de reservas turísticas", Diario La Ley, nº 8319, de 27 de mayo.

BLANQUER CRIADO, D. (1999): “Derecho del Turismo”, Tirant lo Blanch, Valencia. 
BONACHERA VILLEGAS, R. (2008): “El Real Decreto 231/2008, la anhelada modificación del sistema arbitral de consumo", Diario La Ley, $\mathrm{n}^{\circ} 7045$, de 30 de octubre.

BONET NAVARRO, Á. (2015): “La experiencia procesal del fracaso del Derecho”, Universidad de Zaragoza.

CALAZA LÓPEZ, S. (2011): "El binomio procesal: derecho de acción-derecho de defensa, desde la concepción clásica romana hasta la actualidad", Dykinson, Madrid.

CARRIZO AGUADO, D. (2016): "Aspectos jurídicos del contrato de aprovechamiento por turno de bienes de uso turístico ante su comercialización en la esfera internacional", Internacional Journal of World of Tourism", no 5, vol, 3, Sevilla.

CORCHERO PÉREZ, M. A. (2008): “Derecho del Turismo. Conceptos fundamentales”, lustel, Madrid.

DÍAZ ALABART, S. (2005): "El arbitraje de consumo y la nueva Ley de Arbitraje", Revista Actualidad Civil, $n^{\circ} 1$, Madrid, págs. 1285-1302.

DÍEZ-PICAZO, L. M. (2004): “Sistema de derechos fundamentales”, Civitas, Madrid.

ESPÍN ALBA, I. (2013): “Arbitraje y mediación de consumo: a propósito de la Ley 16/2011, de 24 de junio, de contratos de crédito al consumo”, Boletín del Ministerio de Justicia, $\mathrm{n}^{\circ} 2160$, Madrid.

FRANCH FLUXÁ, J. (2015): "Manual de contratación turística”, Atelier, Barcelona.

HERRERO PEREZAGUA, J. F. (2014): "Lo jurisdiccional en entredicho", Thomson Reuters-Aranzadi, Pamplona.

IGLESIAS CANLE, I. C (2011): "Formas de solución de conflictos tras la Ley 13/2009, de 3 de noviembre: especial referencia a la conciliación y mediación”, Dereito, vol. 20, $\mathrm{n}^{\circ} 2$, Universidad de Santiago de Compostela.

MARTÍN DIZ, F. (2010): “La mediación, sistema complementario de Administración de Justicia”, CGPJ, Madrid.

MARTÍNEZ DE SANTOS, A. (2016): "El acto de conciliación en la nueva Ley de Jurisdicción Voluntaria”, Diario La Ley, no 8699, de 10 de febrero.

MONTERO AROCA, J. (2000): “Derecho Jurisdiccional”, Tirant lo Blanch, Valencia.

PÉREZ FERNÁNDEZ, J. M. (2004): “Derecho Público del Turismo”, Thomson-Aranzadi, Pamplona.

PÉREZ FERNÁNDEZ, J. M. (2012): "La armonización de la legislación turística”, III Congreso Internacional de Derecho del Turismo, Palma de Mallorca.

RALUCA STROIE, I.: “¿Es viable un modelo de mediación de consumo autónomo desde el punto de vista de las materias que puedan ser objeto de mediación?", Centro de Estudios de Consumo, Universidad de Castilla-La Mancha, disponible on line.

RAMALLO MIÑÁN, E. del P. (2013): “Manual básico del Derecho Turístico”, Tecnos, Madrid.

ROCA ROCA, E.; CEBALLOS MARTÍN, M. M. y PÉREZ GUERRA, R. (1998): "La regulación jurídica del turismo en España", Universidad de Almería.

RODRIGUEZ-ARANA MUÑOZ, J. (2001): "La distribución de competencias en materia de turismo", Revista de Documentación Administrativa, no 259-260, enero-agosto. 